\title{
In vitro Antioxidant and Anticholinesterase Activities of Ouratea fieldingiana (Gardner) Eng. Leaf Extract and Correlation with Its Phenolics Profile with an in silico Study in Relation to Alzheimer's Disease
}

\author{
Lucas S. Frota, ${ }^{a}$ Daniela R. Alves, ${ }^{\oplus b}$ Leonardo S. Freitas, ${ }^{c}$ Francisco F. S. Lopes, ${ }^{c}$ \\ Marcia M. Marinho, ${ }^{d}$ Emmanuel S. Marinho ${ }^{\circledR e}$ and Selene M. de Morais ${ }^{\circledR} *, a, b, c$
}

a Programa de Pós-Graduação em Biotecnologia, Rede Nordeste de Biotecnologia, Faculdade de Veterinária, Universidade Estadual do Ceará, Campus do Itaperi, 60714-903 Fortaleza-CE, Brazil

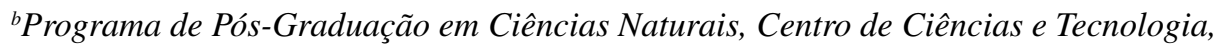
Universidade Estadual do Ceará, Campus do Itaperi, 60714-903 Fortaleza-CE, Brazil

${ }^{c}$ Curso de Química, Centro de Ciências e Tecnologia, Universidade Estadual do Ceará, Campus do Itaperi, 60714-903 Fortaleza-CE, Brazil

${ }^{d}$ Faculdade de Educação, Ciências e Letras de Iguatu, Universidade Federal do Ceará, Campus do Iguatu, 63502-253 Iguatu-CE, Brazil

${ }^{e}$ Grupo de Química Teórica e Eletroquímica, Faculdade de Filosofia Dom Aureliano Matos, Universidade Estadual do Ceará, 62930-000 Limoeiro do Norte-CE, Brazil

\begin{abstract}
Ouratea fieldingiana is a native medicinal plant from Northeastern Brazil and many biological properties are due to the phenolic constituents. The objective of this work was performing the characterization of $O$. fieldingiana leaf constituents to correlate with antioxidant and anticholinesterase activities by in vitro and in silico studies and thus contribute to find new agents against Alzheimer's disease. The high-performance liquid chromatography revealed the presence of the flavonoids rutin, isoquercitrin, kaempferol-3-O-rutinoside, quercetin, apigenin and amentoflavone. The antioxidant activities by the (2,2-diphenyl-1-picrylhydrazyl) (DPPH) and 2,2' -azino-bis(3-ethylbenzothiazoline-6-sulfonic acid) (ABTS) methodologies, showed good results with half maximal inhibitory concentration $\left(\mathrm{IC}_{50}\right)$ values ranging from 5.63 to $11.47 \mu \mathrm{g} \mathrm{mL}^{-1}$ and 2.72 to $23.71 \mu \mathrm{g} \mathrm{mL} \mathrm{m}^{-1}$, respectively. Acetylcholinesterase inhibition assay pointed out the flavone apigenin with best activity. Computational studies evaluated the interaction of flavonoids with the enzyme acetylcholinesterase co-crystallized with the galantamine, used as standard. All flavonoids exhibited binding energy greater than that of galantamine, but only apigenin showed strong interaction with the active site of the enzyme and other bind probably to different allosteric centers. Then, $O$. fieldingiana extract and flavonoids with good anti-radical activity and presenting a broad-spectrum action against acetylcholinesterase (AChE) enzyme ought to be tested in clinical studies to discover new neuro-therapeutic candidates.
\end{abstract}

Keywords: Ouratea fieldingiana, phenolics, acetylcholinesterase, docking, allosteric site

\section{Introduction}

Ouratea fieldingiana (Ocnaceae) is found in the littoral area of Ceará and Rio Grande do Norte States and the plant extracts were considered important source of antioxidants. The biflavonoid amentoflavone was found in

*e-mail: selenemaiademorais@gmail.com

Editor handled this article: Paulo Cezar Vieira the leaf, while the seeds contained a flavonoid glycoside, kaempferol-3-O-rutinoside. Both compounds presented relevant antifungal activity against several Candida strains. An in silico experiment revealed that the compound amentoflavone coupled with the CYP450 protein due to the low energy stabilization $\left(-9.39 \mathrm{kcal} \mathrm{mol}^{-1}\right)$, indicating a possible mechanism of action by inhibition of the ergosterol biosynthesis of Candida fungi. ${ }^{1}$ The effect of kaempferol3-O-rutinoside $(\mathrm{K} 3 \mathrm{R})$ on zebrafish locomotor behavior 
was evaluated with the open field test. K3R did not alter the fish's locomotor system and significantly reduced the orofacial nociceptive behavior induced by all noxious agents compared to the control group. The antinociceptive effect of K3R was similar to morphine. ${ }^{2}$

Several fruit plant polyphenols have been confirmed to be neuroprotective agents, including reducing $\mathrm{A} \beta$ peptide aggregation. In particular, resveratrol, found in grapes and in cereals, tea and peanuts. Polyphenols like the flavonoid quercetin contributes significantly to the protection of neuronal cells against neurotoxicity caused by oxidative stress. $^{3}$

There are reports of plant extracts containing polyphenols that act as scavengers of free radicals, as well as antilipoperoxidants, besides helping to protect collagen from degradation caused by the superoxide anion radical. ${ }^{4}$ Other phenolic constituents act as potentially beneficial lipoxygenase inhibitors, in addition to antioxidant properties, as well as the presence of phenolic compounds in extracts with anticholinesterase activity, which may be potential compounds for the treatment of Alzheimer's disease $(\mathrm{AD}){ }^{5}$

Alzheimer's disease is the most frequent neurodegenerative pathology associated with age, whose cognitive and neuropsychiatric manifestations result in progressive disability and eventual disability ${ }^{6,7}$ In general, the first clinical aspect is the deficiency of recent memory, while remote memories are preserved until a certain stage of the disease.

Acetylcholine (ACh), a neurotransmitter essential for the processing of memory and learning, decreases both in concentration and function in patients with $\mathrm{AD}{ }^{8}$ Acetylcholinesterase (AChE) inhibitors have proven to be the most viable therapeutic target for symptomatic improvement of $\mathrm{AD}$, because cholinergic deficit is a consistent and early finding in $\mathrm{AD},{ }^{9}$ as well, it slows down the degradation of $\mathrm{ACh}$, so the neurotransmitter spends more time in the synaptic cleft, thereby intensifying cholinergic transmission. ${ }^{10}$ Thus, we chose AChE to be the target in our inhibition study to prevent AD.

Oxidative stress generated by free radicals has been identified as an important factor in the development of neurodegenerative diseases such as Alzheimer's disease and most effective drugs for the treatment of $A D$ are inhibitors of the enzyme acetylcholinesterase. With this focus, this work aims to investigate the phenolic profile, antioxidant and anticholinesterase activities of flavonoids contained in the leaf extract of $O$. fieldingiana and develop an in silico study about the action of flavonoids in the AChE.

\section{Experimental}

\section{Chemicals and reagents}

To carry out the experiments, solvents were purchased from the companies Neon (São Paulo, Brazil), Êxodo Cientifica (São Paulo, Brazil) and J.T. BAKER (Radnor, USA). The reagents are from Sigma-Aldrich (St. Louis, USA), Chemical (St. Louis, USA) and Carvalhaes (Alvorada, RS, Brazil). The equipment used is from Eyela Singapore (Bukit Merah, SG), Thermo Fisher Scientific (Massachusetts, USA), Biotek (Vermont, USA) and Shimadzu (Kyoto, Japan).

\section{Preparation of $O$. fieldingiana leaf extract}

The leaves of the Ouratea fieldingiana plant were collected in March 2019, in the municipality of Trairi, Ceará, Brazil. A copy of this exsiccata can be found at the Herbário Prisco Bezerra (EAC) of the Federal University of Ceará (UFC), with the botanical identification of Ouratea fieldingiana (Gardner) Engl. deposited under number 62392 and identified by the botanist Luiz Wilson Lima-Verde on 03/04/2019. The license to access genetic heritage is SisGen A67BFFF.

The leaves of $O$. fieldingiana were collected $(1 \mathrm{~kg})$ dried, ground and submitted to the maceration method with $70 \%$ ethanol in a 1:1 ethanol-material ratio, at room temperature, for a period of 7 consecutive days without renewing the liquid extractor. ${ }^{11}$ The extracting liquid was then filtered and concentrated on a rotary evaporator at a temperature of $65^{\circ} \mathrm{C}$. After this process, two phases were formed a waxy greenish material and a light brown solution which were separated by passing through a Buchner funnel coupled to a kitassato and a vacuum pump, to remove the fatty material containing chlorophyll, and the brown solution was subjected to lyophilization, producing the lyophilized leaf extract (OFE) with a yield of $8.2 \%$.

High performance liquid chromatography (HPLC) coupled to the diode array detector (DAD)

Ouratea fieldingiana extract (OFE) was subjected to high performance liquid chromatography (HPLC-DAD) to identify phenolic compounds, for this, a methanol solution with the extract at a concentration of $20 \mu \mathrm{L} \mathrm{mL}^{-1}$ was injected into the equipment. For this purpose, the analytical standards rutin, isoquercitrin, quercetin, and apigenin were purchased from Sigma Chemical Co. and kaempferol-3-O-rutinoside and amentoflavone were obtained in a previous work with this plant in our laboratory. ${ }^{1}$ The solvents used for extraction 
were of analytical grade (Sigma-Aldrich), and on HPLC, HPLC grade solvents (J.T. BAKER ${ }^{\circledR}$ ) were used. The water was purified with a Milli-Q system (UV Direct3). All samples and solutions prepared for HPLC analysis were filtered through a $0.45 \mu \mathrm{m}$ nylon membrane and $0.22 \mu \mathrm{m}$ membrane filter (Millipore), respectively, before use.

High performance liquid chromatography (HPLC-DAD) was performed with a Shimadzu Prominence Auto Sampler HPLC system (SIL-20A), equipped with Shimadzu LC-20AD alternative pumps connected to a DGU 20A5 degasser with a CBM 20A. integrator, SPD-M20A diode array detector and LC 1.22 SP1 software. Chromatographic analyzes were performed using a Luna $\mathrm{C} 18$ reverse phase column $(4.6 \times 250 \mathrm{~mm}, 5 \mu \mathrm{m})$. The mobile phases $\mathrm{C}$ and D were acetonitrile and Milli-Q water, acidified to $\mathrm{pH} 2.8$ with phosphoric acid, correspondingly, the solvent gradient was used as follows: $0-15 \mathrm{~min}$, an isocratic elution with C:D $(20: 80 \mathrm{v} / \mathrm{v}) ; 17-25 \mathrm{~min}$, linear variation up to C:D $(40: 60 \mathrm{v} / \mathrm{v}) ; 25-40 \mathrm{~min}$, an isocratic elution with C:D $(20: 80 \mathrm{v} / \mathrm{v})$. The flow rate was $1.0 \mathrm{~mL} \mathrm{~min}^{-1}$, with an injection volume of $20 \mu \mathrm{L}$ and wavelength of $350 \mathrm{~nm}$. The initial reference solution was prepared in HPLC methanol in a concentration range of 0.00032 to $1.0 \mathrm{mg} \mathrm{mL}^{-1}$ for rutin; $0.000102-1.0 \mathrm{mg} \mathrm{mL}^{-1}$ for isoquercitrin; 0.008-1.0 $\mathrm{mg} \mathrm{mL}^{-1}$ of kaempferol-3-O-rutinoside; $0.000064-0.2 \mathrm{mg} \mathrm{mL}^{-1}$ for quercetin; 0.0631-0.00097 for apigenin and $0.0016-1.0 \mathrm{mg} \mathrm{mL}^{-1}$ amentoflavone.

The chromatographic peaks of compounds were confirmed by comparing the retention time with the reference standard and the UV spectrum (200 to $400 \mathrm{~nm}$ ). Calibration curve for rutin was $y=4 \times 10^{-8} x+0.005$ (correlation coefficient $(\mathrm{r})=0.999)$; isoquercitrin $y=2 \times 10^{-8} x+0.0136(\mathrm{r}=0.997) ;$ kaempferol-3-O-rutinoside $y=2 \times 10^{-7} x+0.0038(\mathrm{r}=0.999)$; quercetin $y=2 \times 10^{-8} x-$ $0.0001(\mathrm{r}=0.999)$; apigenin $y=1 \times 10^{-8} x+0.0001$ and amentoflavone $y=4 \times 10^{-7} x-0.0306(\mathrm{r}=0.982)$. OFE was analyzed by dissolving in methanol at a concentration of $20.00 \mathrm{mg} \mathrm{mL}^{-1}$. The sample was analyzed in triplicate and the mean peak areas were measured.

\section{In vitro evaluation of acetylcholinesterase inhibition}

The acetylcholinesterase quantitative enzyme inhibition test used the following reagents per well: $25 \mu \mathrm{L}$ of acetylthiocholine iodide $(15 \mathrm{mM}), 125 \mu \mathrm{L}$ of 5.5 '-dithiobis[2-nitrobenzoic] in the $0.1 \mathrm{M}$ Tris/ $\mathrm{HCl}$ solution $\mathrm{NaCl}$ and $0.02 \mathrm{M} \mathrm{MgCl}_{2} \cdot 6 \mathrm{H}_{2} \mathrm{O}, 50 \mu \mathrm{L}$ of Tris/ $\mathrm{HCl}$ solution with $0.1 \%$ bovine serum albumin, $25 \mu \mathrm{L}$ of samples/standards, the standards of physostigmine (eserina) and galantamina, separately, and $25 \mu \mathrm{L}$ of $\mathrm{AChE}\left(0.22 \mathrm{unit}, \mathrm{uL}^{-1}\right)$. The inhibitory activity of the acetylcholinesterase enzyme (AChE) was measured in 96-well flat-bottom plates using an ELISA BIOTEK reader, model ELX 800, software Gen5 V2.04.11. based on the methodology described by Ellman et al. ${ }^{12}$

To determine whether the positive results presented in the microplate assay were due to enzymatic inhibition or inhibition of the chemical reaction between Ellman's reagent (5,5-dithiobis-(2-nitrobenzoic acid) or DTNB) and thiocholine, the reaction kinetics of each well were observed, and the color of the samples was extinguished from the analysis by reading the microplate before and after enzymatic addition. The same analyzes were also performed with the positive control (galantamine and physostigmine), the negative control (all solutions except the sample and/or standard) and the blank (all solutions except the sample and/or standard + methanol). All samples were diluted in methanol, prepared in $2 \mathrm{mg} \mathrm{mL}^{-1}$ solutions and mean inhibitory concentration $\left(\mathrm{IC}_{50}\right)$ calculated from the following curve of evaluated concentrations: 200,100 , $50,25,12.5,6.25,3.12,1.56$, and $0.78 \mu \mathrm{gL}^{-1}$. The values

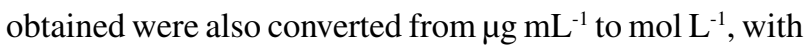
the exception of the value for the extract.

\section{Determination of antioxidant activity by the DPPH method}

The antioxidant activity was measured in 96-well flatbottom plates using an Elisa BioTek reader, model ELX 800, software Gen5 V2.04.11, based on the methodology described by Becker et al. ${ }^{13}$ with modifications. In 96-well plates, the following solutions were used per well: $180 \mu \mathrm{L}$ of methanolic solution of DPPH (2,2-diphenyl-1-picrylhydrazyl), $20 \mu \mathrm{L}$ of the extract sample dissolved in methanol and diluted 10 times to obtain final concentration $0.2 \mathrm{mg} \mathrm{mL}^{-1}$.

Various concentrations of the samples were prepared using the initial solution with a concentration of $2 \mathrm{mg} \mathrm{mL}^{-1}$ : $200,100,50,25,12.5,6.25,3.12,1.56$, and $0.78 \mu \mathrm{gL}^{-1}$. Absorbances were measured at $490 \mathrm{~nm}$ until a total of 60 min of incubation. For the negative control, a solution was prepared containing all the reagents, except the sample. The absorbances relative to the extract's colors were extinguished from the analysis. Butylated hydroxytoluene (BHT) antioxidant was used for comparison.

The results are expressed as percentage of inhibition (PI), calculated by $\mathrm{PI}(\%)=[(\mathrm{AC}-\mathrm{AS}) / \mathrm{AC}] \times 100$, where $\mathrm{AC}$ is absorbance of the $\mathrm{DPPH} \cdot$ control solution at time 0 and AS is the absorbance of the sample solution containing DPPH at time $60 \mathrm{~min}$. All samples were analyzed in triplicate.

\section{Assessment of antioxidant activity by the ABTS method}

Antioxidant activity was assessed using the ABTS (2,2'-azino-bis(3-ethylbenzothiazoline-6-sulfonic acid)) 
method, as described by Re et al. ${ }^{14}$ The $\mathrm{ABTS}^{\bullet+}$ solution ( $7 \mathrm{mM}, 5 \mathrm{~mL}$ ) was mixed with $88 \mu \mathrm{L}$ of potassium persulfate $(140 \mathrm{mM})$, agitated, and kept in the dark at room temperature for $16 \mathrm{~h}$. Then, $1 \mathrm{~mL}$ of this solution was added to $99 \mathrm{~mL}$ of ethanol, and the absorbance was measured at $734 \mathrm{~nm}$. A series of solutions of the plant extracts with decreasing concentrations was prepared, and $3.0 \mathrm{~mL}$ of ABTS $^{-+}$solution was added to $30 \mu \mathrm{L}$ of these solutions after $6 \mathrm{~min}$. The absorbance was then measured at $734 \mathrm{~nm}$. The $\mathrm{IC}_{50}$ values were calculated by linear regression. All samples were analyzed in triplicate.

\section{Molecular docking of OFE flavonoids targeting acetylcholinesterase}

\section{Computational details}

The simulations were performed on the 64-bit software operating system. The software used were, UCSF Chimera $^{\mathrm{TM}},{ }^{15}$ Autodocktools ${ }^{\mathrm{TM}},{ }^{16}$ AutoDockVina ${ }^{\mathrm{TM}},{ }^{17}$ Avogadro $^{\text {TM }}{ }^{18}$ Morpheus $^{\circledR 19}$ online statistical tool and Discovery Studio Visualizer ${ }^{\mathrm{TM}}$ viewer. $^{20}$

\section{Obtaining the 3D structure of the target protein}

The structure of acetylcholinesterase was obtained from the Protein Data Bank protein repository using the PDB code 4EY6, ${ }^{21}$ identified as Crystal Structure of Recombinant Human Acetylcholinesterase co-crystallized with the inhibitor (-) galantamine (GNT), determined from $\mathrm{X}$-ray diffraction, deposited with $2.3 \AA$ resolution. The enzyme treatment was carried out from the removal of all residues and original ligands, followed by the insertion of polar hydrogen $(\mathrm{H})$ atoms..$^{22,23}$ The crystallization water molecules were removed and amino acid residues forming the binding site were protonated. Its structure at the end of the preparation for molecular docking was saved in PDBQT format. ${ }^{23,24}$ Redocking of the cocrystallized (galantamine) ligands was realized to validate the docking protocol. All the ligands were separately evaluated at molecular studies.

\section{Preparation and optimization of ligands}

The two-dimensional structures of flavonoids characterized in $O$. fieldingiana amentoflavone, kaempferol3-O-rutinoside, quercetin, isoquercitrin, apigenin and rutin were obtained from the PubChem ${ }^{\oplus 25}$ virtual repository. For the treatment of ligands, the Avogadro code was used, ${ }^{26}$ applying the Merck Molecular Force Field 94-MMFF94 force field and descending steepest algorithm with cycles of 10 interactions, 500 number steps, and a $10 \mathrm{e}^{-7}$ convergence parameter. ${ }^{27}$ Subsequently the molecules were converted to ligand mol2.

\section{Molecular docking procedure}

The use of computational methods has become a quick and more accessible alternative for those looking to investigate the medicinal potential of molecules. ${ }^{23,28}$ Thus, the computational method of molecular docking can be defined as the orientation assumed by the ligand at the enzyme binding site, based on the application of an algorithm that promotes conformational searches guided by an energy grid in a delimited area of the receptor and by using the scoring function to identify the conformation of the ligand with the lowest free energy of computationally viable bond. ${ }^{29-32}$ Based on this, the molecular docking method was performed in one hundred independent runs for amentoflavone, kaempferol-3-O-rutinoside, rutin, isoquercitrin, apigenin and quercetin with acetylcholinesterase using Lamarckian genetic algorithm, which is implemented as an algorithm local search ${ }^{33}$ of AutoDock Vina code; the search grid was delimited with the parameters center_x $=-0.412$, center_y $=-51.388$, center_z $=4.1$, size_x $=84$, size_y $=92$, size_z $=126$, spacing $=1,000$, exhaustiveness $=8$ and 3-way multithreading, being generated at the end of each docking ten nine conformations of the ligand to the protein target. The 2D diagram of intermolecular interactions performed by the grouping formed between the ligands and acetylcholinesterase was generated using the Discovery Studio Visualizer and the three-dimensional visualization of the receptor-ligand grouping was performed using the UCSF Chimera visualizer. ${ }^{34}$ The data obtained from the analysis were plotted on the Morpheus ${ }^{\circledR}$ online statistical tool, where heat maps were generated to identify the ligandresidue interaction and similarity profiles by the statistical test Pearson. The types of ligand-residue interactions, as well as the figures, were generated using the Discovery Studio $^{\circledR}$.

\section{Results and Discussion}

Characterization of the flavonoids present in the Ouratea fieldingiana ethanol extract (OFE) by high performance liquid chromatography (HPLC) coupled to a diode array detector (DAD)

The phenolic compounds identified and quantified in the ethanolic extract of $O$. fieldingiana leaves, through the analysis in HPLC-DAD, are shown in Table 1 where the major components were amentoflavone (AMT), a biflavonoid, followed by rutin, and kaempferol3-O-rutinoside, flavonoid glycosides. These flavonoids have several reports of decreasing the production of nitric 
oxide (NO) and the expression of the enzyme iNOS ${ }^{35,36}$ and also inhibit AChE. ${ }^{37,38}$

Table 1. Quantification of phenolic compounds from the ethanolic extract of the leaves of Ouratea fieldingiana analyzed by high performance liquid chromatography

\begin{tabular}{lcc}
\hline Component & Extract $/\left(\mathrm{mg} \mathrm{g}^{-1}\right)$ & $\mathrm{t}_{\mathrm{R}} / \mathrm{min}$ \\
\hline Rutin & $47.92 \pm 0.53$ & 6.47 \\
Isoquercitrin & $24.23 \pm 0.25$ & 7.91 \\
Kaempferol-3-O-rutinoside & $47.46 \pm 1.17$ & 9.38 \\
Quercetin & $6.81 \pm 0.11$ & 22.36 \\
Apigenin & $1.96 \pm 0.02$ & 24.75 \\
Amentoflavone & $86.88 \pm 1.08$ & 27.17 \\
\hline
\end{tabular}

$\mathrm{t}_{\mathrm{R}}:$ retention time.

In vitro evaluation of antioxidant and anticholinesterase activities

The antioxidant activity of flavonoids is displayed in Table 2 and all compounds showed antioxidant activity close to the gallic acid standard. In relation to DPPH assay, compounds are considered to have high or significant antioxidant capacity when $\mathrm{IC}_{50}<10 \mu \mathrm{g} \mathrm{mL}-1$, moderate antioxidant capacity when $10<\mathrm{IC}_{50}<20 \mu \mathrm{g} \mathrm{mL}^{-1}$, and low antioxidant capacity when $\mathrm{IC}_{50}<20 \mu \mathrm{g} \mathrm{mL}^{-1}$. It was observed an excellent antioxidant activity having as reference the study carried out by Ngameni et al. ${ }^{39} \mathrm{In}$ relation to the flavonoid structure, a free 3-hydroxyl group (C ring) and 3',4'-catechol (dihydroxy) structure (B ring), a 2-3 double bond, and a 4-oxo group confers superior activity to the flavonoid. Glycosidic substitution decreases antioxidant actitvity. ${ }^{40}$ Amentoflavone, rutin and quercetin present antiradical activity similar to gallic acid by DPPH test and by ABTS assay quercetin, isoquercetin and rutin were even more active than gallic acid.
Gibson and Huang ${ }^{41}$ document the oxidative stress in brains and peripheral tissues of patients with $\mathrm{AD}$, as well as in animal models with $\mathrm{AD}$, showing the relationship that exists between $\mathrm{AD}$ and oxidative processes. If oxidizing species are important in inducing AD-related changes, then antioxidants that scavenge these species could prevent AD-related abnormalities caused by oxidants in the brain. ${ }^{41}$

The results obtained for the flavonoids from O. fieldingiana in the inhibition of AChE activity were compared to that of the alkaloid physostigmine, which are the first discovered natural inhibitor. Santos et al..$^{42}$ determined the anticholinesterase activity of extracts and fractions from 54 plants and classified the action according to the $\mathrm{IC}_{50}$ values as high potency when $\mathrm{IC}_{50}<20 \mu \mathrm{g} \mathrm{mL}^{-1}$. Then, the OFE and flavonoids from $O$. fieldingiana demonstrated good activities since $\mathrm{IC}_{50}$ ranged from 3.12 to $12 \mu \mathrm{g} \mathrm{mL} \mathrm{m}^{-1}$ as shown in Table 3 .

The AChE inhibitory activity of flavonoids can be related to the number and position of hydroxyl groups and the unsaturation of the $\mathrm{C}$-ring. The combination of the $\mathrm{C} 5-\mathrm{OH}$, $\mathrm{C} 6-\mathrm{OH}$ and $\mathrm{C} 7-\mathrm{OH}$ groups provide strong inhibition of $\mathrm{AChE}$ activity. The $\mathrm{IC}_{50}$ determinations also indicated the participation of the flavonoids B-ring $\mathrm{C}^{\prime}-\mathrm{OH}$ in $\mathrm{AChE}$ inhibition. Another structural feature contributing towards strong inhibitory activity is the $\mathrm{C}$-ring double bond between $\mathrm{C} 3$ and $\mathrm{C} 4$. The unsaturation of the C-ring is known to increase planarity of the chroman moiety in the flavonoid structure that enhanced, amongst other things, antioxidant activity. The C-ring $\mathrm{C} 3-\mathrm{OH}$ in flavonols does not appear to contribute to inhibitory activity of $\mathrm{AChE}$ and steric hindrance due to the presence of a sugar moiety at the $\mathrm{C} 3-\mathrm{OH}$ site decreases inhibitory activity. ${ }^{43}$ Studies using several flavonoids, in order to evaluate the anticholinergic effect in pre-clinical assays, show the potential of these metabolites as prototypes for anti-AChE drugs. ${ }^{44,45}$ These observations

Table 2. $\mathrm{IC}_{50}$ values for $\mathrm{DPPH} \bullet$ and $\mathrm{ABTS}^{\bullet+}$ radicals' inhibition

\begin{tabular}{|c|c|c|c|c|}
\hline \multirow{3}{*}{ Compound } & \multicolumn{4}{|c|}{$\mathrm{IC}_{50}$} \\
\hline & \multicolumn{2}{|c|}{$\mathrm{DPPH} \bullet$} & \multicolumn{2}{|c|}{ ABTS $^{\bullet+}$} \\
\hline & $\left(\mu \mathrm{g} \mathrm{mL}^{-1}\right)$ & $\left(\mu \mathrm{mol} \mathrm{mL} L^{-1}\right)$ & $\left(\mu \mathrm{g} \mathrm{mL}^{-1}\right)$ & $\left(\mu \mathrm{mol} \mathrm{mL} L^{-1}\right)$ \\
\hline Ascorbic acid (standard) & $1.94 \pm 0.27^{\mathrm{a}}$ & $11.01 \pm 1.53$ & $11.90 \pm 0.26^{\mathrm{d}}$ & $67.56 \pm 1.47$ \\
\hline Gallic acid (standard) & $6.18 \pm 0.10^{b}$ & $36.3 \pm 0.07$ & $10.78 \pm 0.03^{c}$ & $63.36 \pm 0.17$ \\
\hline OFE & $11.47 \pm 0.20^{\mathrm{e}}$ & - & $23.71 \pm 0.13^{\mathrm{f}}$ & - \\
\hline Amentoflavone & $5.63 \pm 0.08^{\mathrm{b}}$ & $10.4 \pm 0.14$ & $11.25 \pm 0.47^{\mathrm{h}}$ & $32.32 \pm 0.87$ \\
\hline Kaempferol-3-O-rutinoside & $9.80 \pm 0.17^{\mathrm{d}}$ & $16.4 \pm 0.28$ & $20.02 \pm 0.15^{g}$ & $44.41 \pm 0.25$ \\
\hline Rutin & $6.09 \pm 0.03^{b}$ & $9.97 \pm 0.04$ & $4.34 \pm 0.20^{\mathrm{b}}$ & $7.10 \pm 0.32$ \\
\hline Quercetin & $6.05 \pm 0.23^{\mathrm{b}}$ & $20.0 \pm 0.76$ & $2.72 \pm 0.13^{\mathrm{a}}$ & $8.99 \pm 0.43$ \\
\hline Isoquercitrin & $8.74 \pm 0.60^{c}$ & $18.8 \pm 0.12$ & $9.73 \pm 0.78^{c}$ & $20.97 \pm 1.67$ \\
\hline Apigenin & $9.72 \pm 0.18^{\mathrm{d}}$ & $35.9 \pm 0.66$ & $21.58 \pm 0.21^{\mathrm{e}}$ & $79.91 \pm 0.77$ \\
\hline
\end{tabular}

Different small letters mean statistically different results $\left(p<0.001\right.$, ANOVA followed by Tukey's test). $\mathrm{IC}_{50}$ : half maximal inhibitory concentration; DPPH: 2,2-diphenyl-1-picrylhydrazyl; ABTS: 2,2'-azino-bis(3-ethylbenzothiazoline-6-sulfonic acid); OFE: Ouratea fieldingiana extract. 
are in accordance with the results shown in Table 3, where the flavone apigenin shows best anti-AChE activity and amentoflavone, which structure correspond to a dimer of apigenin was less active, probably due to steric hindrance.

Table 3. $\mathrm{IC}_{50}$ values for acetylcholinesterase inhibition

\begin{tabular}{lcc}
\hline \multirow{2}{*}{ Compound } & \multicolumn{2}{c}{$\mathrm{IC}_{50}$} \\
\cline { 2 - 3 } & $\left(\mu \mathrm{g} \mathrm{mL}^{-1}\right)$ & $\left(\mu \mathrm{mol} \mathrm{mL} \mathrm{m}^{-1}\right)$ \\
\hline Physostigmine (standard) & $1.15 \pm 0.05^{\mathrm{a}}$ & $4.17 \pm 0.05$ \\
Galantamine (standard) & $1.02 \pm 0.02^{\mathrm{a}}$ & $3.54 \pm 0.02$ \\
OFE & $11.56 \pm 0.10^{\mathrm{e}}$ & - \\
Amentoflavone & $8.68 \pm 0.73^{\mathrm{d}}$ & $16.12 \pm 1.35$ \\
Kaempferol-3-O-rutinoside & $8.94 \pm 0.45^{\mathrm{d}}$ & $15.03 \pm 0.75$ \\
Rutin & $12.00 \pm 0.13^{\mathrm{f}}$ & $19.65 \pm 0.21$ \\
Quercetin & $6.28 \pm 0.06^{\mathrm{c}}$ & $20.77 \pm 0.19$ \\
Isoquercitrin & $3.15 \pm 0.03^{\mathrm{b}}$ & $67.87 \pm 0.06$ \\
Apigenin & $3.12 \pm 0.04^{\mathrm{b}}$ & $11.55 \pm 0.14$ \\
\hline
\end{tabular}

Different small letters mean statistically different results $(p<0.001$, ANOVA followed by Tukey's test). OFE: Ouratea fieldingiana extract. $\mathrm{IC}_{50}$ : mean inhibitory concentration.

\section{Evaluation of in silico results}

With the positive in vitro evaluations for the AChE inhibitory capacity of the flavonoids from $O$. fieldingiana, in silico studies were performed. The results of free energy value $(\Delta G)$ interactions of the compounds with the enzyme confirmed the inhibition potential of these compounds as shown in Table 4. The computational analysis revealed that flavonoids from $O$. fieldingiana had better interactions with AChE enzyme than standard galantamine, demonstrating $\Delta \mathrm{G}$ energies (Gibbs free energy/affinity free energy) ranging from -8.2 to $-10.1 \mathrm{kcal} \mathrm{mol}^{-1}$.

Table 4. Best connection free energy value $(\Delta \mathrm{G})$ and root mean square deviation (RMSD) for each linker

\begin{tabular}{lcc}
\hline Binder & $\Delta \mathrm{G} /\left(\mathrm{kcal} \mathrm{mol}^{-1}\right)$ & $\mathrm{RMSD} / \AA$ \\
\hline Galantamine (standard) & -7.3 & 1.82 \\
Amentoflavone & -10.1 & 0.975 \\
Kaempferol-3-O-rutinoside & -9.2 & 1.651 \\
Isoquercitrin & -8.7 & 1.163 \\
Rutin & -9.3 & 1.686 \\
Quercetin & -8.2 & 1.749 \\
Apigenin & -10.1 & 1.187 \\
\hline
\end{tabular}

Acetylcholinesterase complexed with galantamine is an enzyme composed by two dimer chains (A and B) as shown in Figure 1a. Galantamine, a natural alkaloid used as a standard medication for $\mathrm{AD}$, binds to the serine of the AChE active site, through the carbamyl group, ${ }^{46}$ inactivating the protein and prolonging the duration and intensity of neuronal stimulation by acetylcholine at the synaptic terminals. The computational simulations made with flavonoids from $O$. fieldingiana and $\mathrm{AChE}$ in this study showed their molecular interactions at different sites of activity (Figure 1b), in relation to the two active sites of galantamine in the dimeric structure (Figure 1c). However, surprisingly, only apigenin binds to the active site where GNT binds (Figure 1c).

Comparing the calculated distances between the six flavonoids and the amino acid residues from the AChE active site where GNT binds (Table 5), it can be seen that apigenin shows interaction with 7 amino acids from the active site of GNT, obtaining better performance than GNT in 4 of them (Trp86, Gly120, Gly121 and Tyr337), followed by amentoflavone. It is important to note that amentoflavone has shown an attraction for the active site of GNT, as this molecule is a dimer of apigenin. However, amentoflavone has a larger molecular structure than the other compounds and probably was unable to fully bind to the main catalytic active site of galantamine. Nevertheless, there are interactions of moderate force attraction with 3 amino acid residues from the GNT site characterizing probably an occurrence of a close new binding center (allosteric site) shown in Figure 1a III, and highlighted by black dotted circle in Figure 1b III with a high degree of bonding stability (Table 3). These data lead us to the assumption that the kaempferol-3-O-rutinoside, isoquercitrin, rutin, quercetin and amentoflavone flavonoids probably bind also to other two other allosteric centers (Figure 1a I and II) in the AChE dimer structure, causing the protein inactivity found in in vitro assays.

In Figure 1b, with an emphasis on the yellow spheres, the compounds kaempferol-3- $O$-rutinoside, isoquercitrin and rutin are linked in chain A (allosteric site I) and quercetin in chain B (allosteric site II) of AChE, characterizing these sites in the central region of the protein. Amentoflavone, on the other hand, is bound to the allosteric site III, close to the active site of GNT. It is important to note that the active protein sites shown in these studies have completely different electron affinity configurations. The kaempferol3-O-rutinoside ligand exhibited strong conventional electrostatic hydrogen bonding interactions with Arg525 and $\operatorname{Gln} 527$ ( 2.77 to $2.14 \AA$ ) and $5 \pi$ type interactions with Ala397, Ala528, Tyr382, Gln527, Arg525 (4.19 to $5.83 \AA$ ). The bonds formed between isoquercitrin-AChE and rutin-AChE have also been identified in the same site. Two conventional strong hydrogen bonds were observed, one between isoquercitrin and the amino acid Asp400 (1.87 $\AA$ ) and the other between rutin and the Gln527 residue (1.98 ̊). Quercetin-AChE presented two conventional hydrogen bonds with residues Lys332 and Arg525 (2.83 to $3.51 \AA$ ) and $\pi$-alkyl bonds with Ala526 (5.32 ̊). Then 

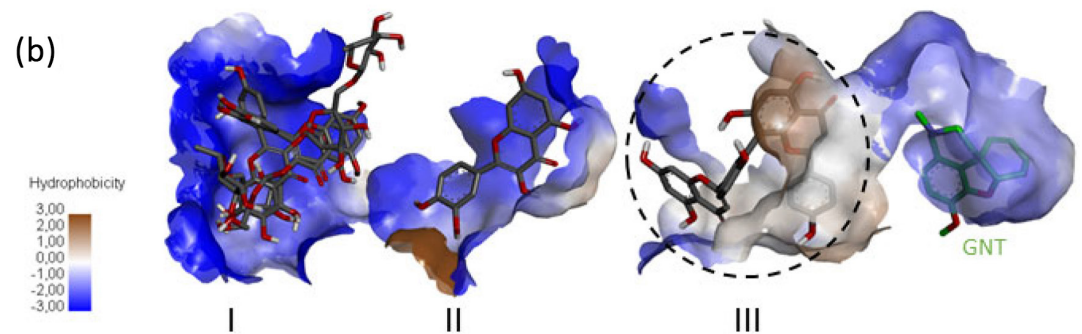

III

Alosteric Sites

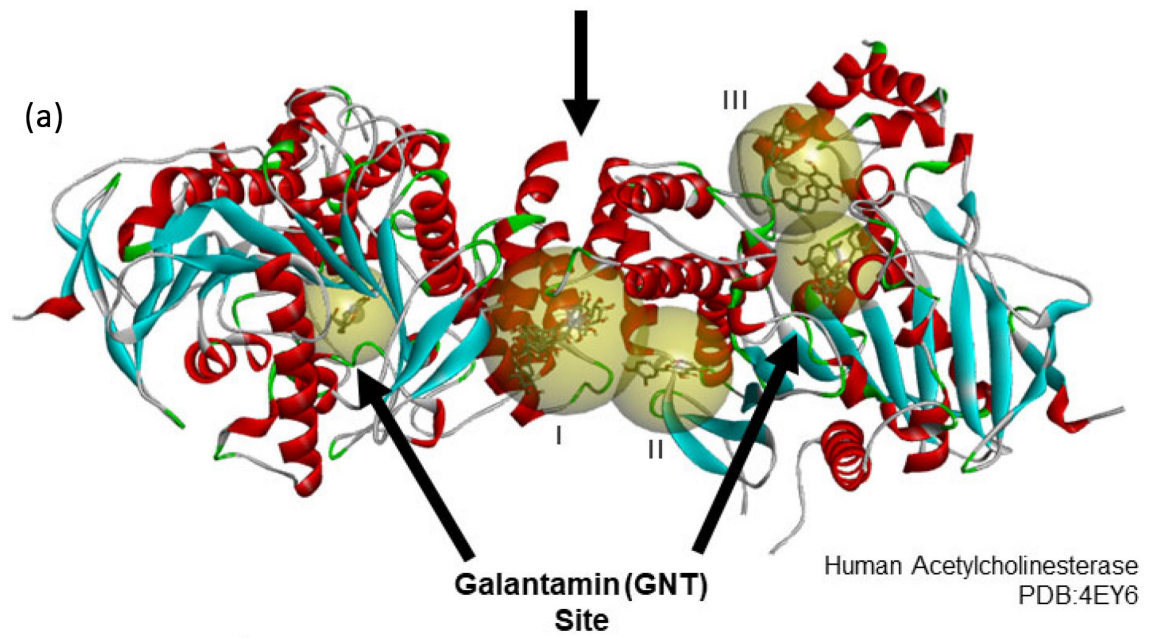

(c)

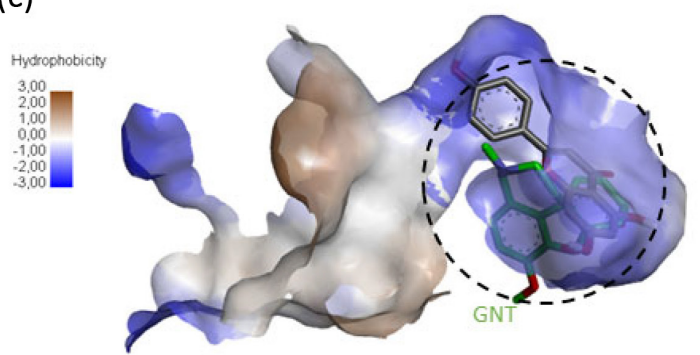

Figure 1. Simulation of molecular interactions: (a) ligands with acetylcholinesterase; (b) allosteric sites of acetylcholinesterase; (c) acetylcholinesterase active site.

Table 5. Distances of acetylcholinesterase (AChE) residues of the active site where galantamine (GNT) (standard) binds

\begin{tabular}{|c|c|c|c|c|c|c|c|}
\hline $\begin{array}{l}\text { AChE residue } \\
\text { (GNT site) }\end{array}$ & AMT / Å & K3R / Å & Isoquercitrin / $\AA$ & Rutin / A & Quercetin / A & Apigenin / $̊$ & GNT (standard) / \\
\hline Trp86 & 9.2 & 23.2 & 23.2 & 23.0 & 17.3 & 3.2 & 3.8 \\
\hline Gly 120 & 11.7 & 26.6 & 25.3 & 25.1 & 20.2 & 3.3 & 4.0 \\
\hline Gly121 & 8.0 & 25.2 & 25.1 & 24.6 & 21.3 & 3.4 & 4.1 \\
\hline Gly122 & 7.2 & 23.7 & 23.9 & 23.3 & 20.8 & 5.2 & 4.1 \\
\hline Ser $203^{a}$ & 9.4 & 20.4 & 20.0 & 19.7 & 15.9 & 4.8 & 3.4 \\
\hline Phe295 & 5.1 & 15.1 & 15.2 & 14.7 & 14.1 & 8.6 & 3.4 \\
\hline Phe297 & 3.1 & 20.4 & 21.4 & 20.0 & 19.6 & 7.7 & 3.9 \\
\hline Tyr337 & 5.8 & 13.6 & 13.5 & 13.6 & 13.6 & 2.8 & 3.3 \\
\hline His 447 & 9.0 & 15.2 & 15.5 & 15.3 & 12.6 & 3.9 & 3.1 \\
\hline
\end{tabular}

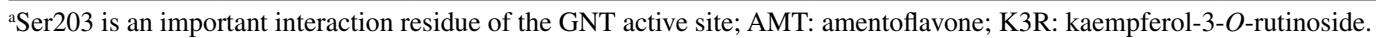

the new active site, the residues His381, Tyr382, Ala397, Asp400, Arg525 and Gln527 were shown to be important and conserved. Amentoflavone showed nine interactions with acetylcholinesterase, highlighting the four conventional hydrogen bond interactions, one with Asp74 (1.88 $⿱$ ) and $\operatorname{Arg} 296(2.18 \AA)$ and two with Ser293 (2.13 and $2.52 \AA)$. 
The results demonstrated that these biologically active flavonoids are able to interact with $\mathrm{AChE}$ in active site and allosteric sites, inhibiting the enzymatic action. Thus, these allosteric sites proposed can be used for future analysis of compounds for inhibition of the AChE enzyme. Even so, it is important to mention that the flavonoids were evaluated separately in relation to the enzyme, and it is not possible to observe by this analysis whether these compounds would act synergistically against the target. Thus, further studies are necessary to assess the in vitro or in vivo synergistic potential. Nevertheless, these compounds bind to different points in the enzyme, then they can potentially act together and increase inhibition of enzyme activity.

\section{Evaluation of molecular docking with the target on} acetylcholinesterase active and allosteric centers

The protein surface of the active site (Figure 1c) is from a deep protein cavity with hydrophobic and hydrophilic electrostatic elements capable of attracting GNT (standard), among other bioactive substances. The possible allosteric sites I, II and III (Figure 1b) are characterized by an open, predominantly hydrophilic cavity, in the dimeric structure of acetylcholinesterase. The results lead to the conclusion that alterations in any allosteric site can alter the three-dimensional conformation in the active GNT site, previously described. Thus, even when a bioactive substance is bound only to the allosteric site, it can have the same potential for enzymatic inhibition.

For comparison of the calculated distances between the ligands and the residues of the GNT binding site (Table 5), a statistical analysis was performed and expressed by the heat map (Figure 2). In Figure 2a, the greater the force of interaction, the more reddish the color, low force more bluish. Clusters are identified by the presence of green squares. Through this analysis it is possible to understand the formation of three clusters, identified by the presence of green squares, showing the statistical difference between

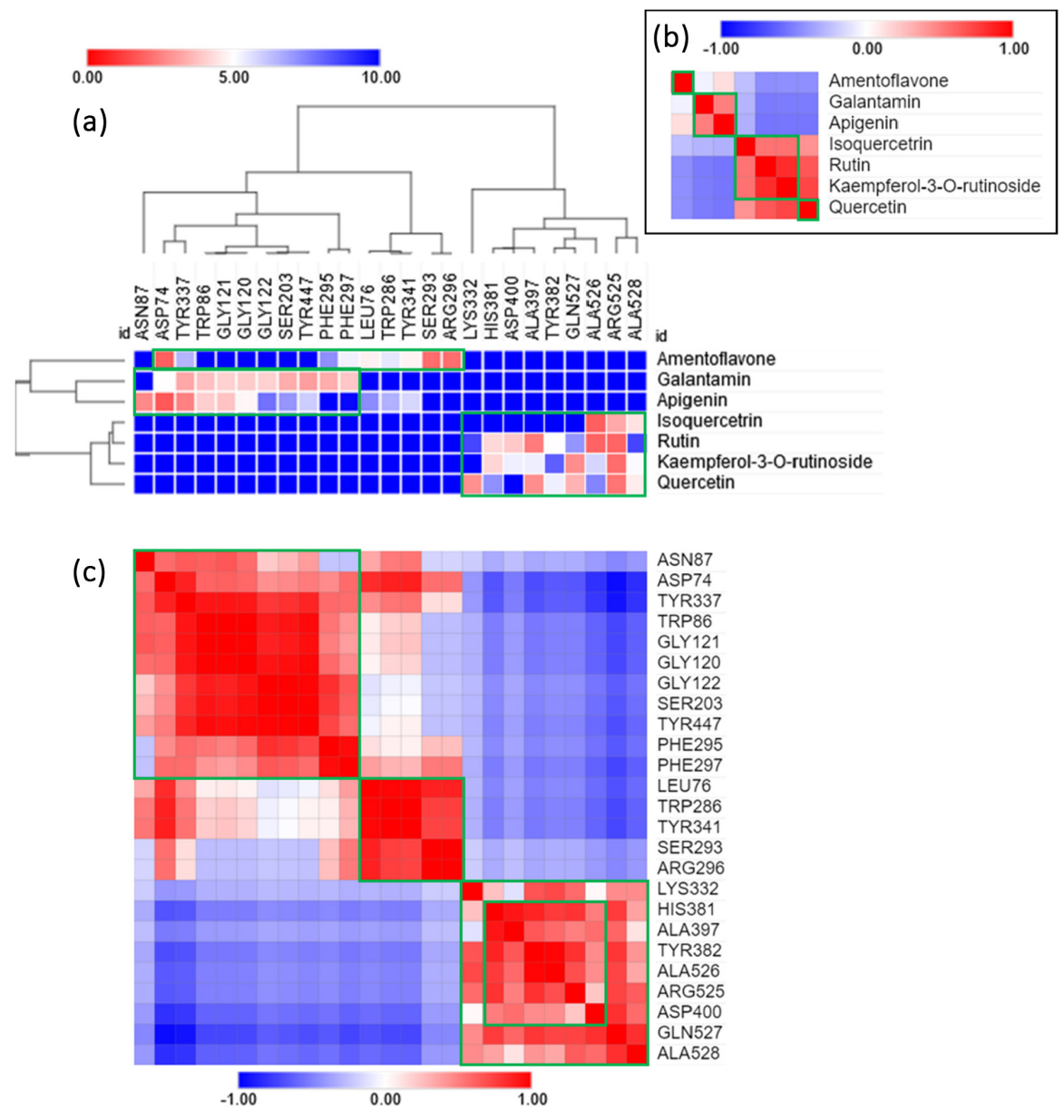

Figure 2. Heatmap panel illustrating statistically regarding interactions with AChE enzyme. (a) The relationships between ligands (Y axis) and residues (X axis); (b) between ligands and (c) between residues, as well as identification of the ligands arranged on the panel's Y axis (d). In (a) graphic, the closer to 0 (red) the interaction force is more determinant and intense, the closer to 10 (blue) the greater the distance and the interaction force is negligible. In (b-c) layouts, the closer to 1 (red) the interaction force will be more determinant and intense, the closer to -1 (blue) the greater the distance and the interaction force will be negligible. Clusters highlighted by green squares. 
the sites, as well as the interaction strength of each compound with each residue.

In Figure 2b, regarding the similarity between the connections made by the ligands, there is the approximation between apigenin and GNT, the others clusters found are composed for other $O$. fieldingiana flavonoids. In Figure 2c, the conserved residues of the active site, where GNT bind, are main Trp86, Asn87, Gly120 and Gly121. For the allosteric sites featured in this work, the connections made with Ala397, Arg525, Ala526, Gln527 and Ala528 for site I; His381, Lys332 for site II and Ser293, Arg296 for site III seems to be decisive. Then, the presence of three allosteric sites is again evidenced here, by another statistical method, as new centers that can act as an activity regulator.

The active site of AChE is subdivided into several subsites: catalytic triad in the base of the gorge, anionic subsite (AS), acyl-binding pocket, and peripheral anionic subsite (PAS) at the mouth of the site, being PAS an allosteric site. Modulators binding PAS limit the catalytic efficiency in two ways, combining steric and electrostatic blockage of ligand and changing the active site conformation. ${ }^{47}$ In relation to compounds acting in allosteric sites of AChE, the combination of the nuclear magnetic resonance (NMR) spectroscopy based data with molecular modelling detect a new possible binding site in AChE, called site B, located outside the catalytic gorge where rosmarinic acid was able to bind; however, its allosteric functioning is not clear. ${ }^{40}$ In the analysis of docking molecular simulations performed with $O$. fieldingiana components, it was demonstrated that all compounds have binding affinity with AChE better than the standard galantamine and among all compounds only apigenin bind to the active site of acetylcholinesterase. However, amentoflavone bind next to the active site but not directly, kaempferol-3-O-rutinoside, amentoflavone, rutin, quercetin and isoquercitrin also did not bind to the active site of the enzyme AChE (co-crystallized).

Then flavonoids from $O$. fieldingiana which inhibit in vitro $\mathrm{AChE}$ but not bind to the same site as galantamine, link probably to allosteric sites, which can be used in the analysis of new bioactive substances to determine activity potential for the discovery of new drugs to fight Alzheimer's disease.

\section{Conclusions}

The $O$. fieldingiana extract showed antioxidant and anti-cholinesterase activity, which is supported by the presence of flavonoids which scavenge free radicals and inhibit acetylcholinesterase enzyme. Nevertheless, the sites of inhibition of AChE are not the same for all flavonoids, some of them bind directly to the active site and other bind to different allosteric regions. Then, $O$. fieldingiana extract and flavonoids with good anti-radical activity and presenting a broad-spectrum action against AChE enzyme are interesting natural products to be tested in clinical studies to discover new neuro-therapeutic candidates.

\section{Acknowledgments}

Laboratory of Chemistry of Natural Products (LQPN) of the Ceará State University (UECE), National Center for High Performance Processing (CENAPAD) of the Federal University of Ceará (UFC) and Ceará Foundation of Support for Scientific and Technological Development (FUNCAP, Brazil) for the LF scholarship funding and research projects. We also thank Luiz Wilson Lima-Verde for the exsiccate deposit at Prisco Bezerra herbarium of Federal University of Ceará.

\section{Author Contributions}

S. M. M. and E. S. M. designed the research and provided conditions, L. S. F. carried out the experiments, with the assistance of D. R. A., L. S. F., F. F. S. L., and M. M. M.; S. M. M. and E. S. M. supervised the work and all authors participated in the writing and editing of the manuscript.

\section{References}

1. Nascimento, J. E. T.; Rodrigues, A. L. M.; Lisboa, D. S.; Liberato, H. R.; Falcão, M. J. C.; da Silva, C. R.; Nobre Jr., H. V.; Braz Filho, R.; Paula Jr., V. F.; Alves, D. R.; Morais, S. M.; Evidence-Based Complementary Altern. Med. 2018, ID 1748487.

2. Nascimento, J. E. T.; Morais, S. M.; Lisboa, D.; Sousa, M.; Santos, S.; Magalhães, F. E.; Campos, A.; Biomed. Pharmacother 2018, 107, 1030.

3. de Falco, A.; Cukierman, D. S.; Hauser-Davis, R. A.; Rey, N. A.; Quim. Nova 2016, 39, 63.

4. Chen, J. H.; Ho, C.-T.; J. Agric. Food Chem. 1997, 45, 2374.

5. Morais, S. M.; Lima, K. S. B.; Siqueira, S. M. C.; Cavalcanti, E. S. B.; Souza, M. S. T.; Menezes, J. E. S. A.; Trevisan, M. T. S.; Rev. Bras. Plant. Med. 2013, 15, 575.

6. Zhao, Q.; Tang, X. C.; Eur. J. Pharmacol. 2002, 455, 101.

7. Janus, C.; Westaway, D.; Physiol. Behav. 2001, 73, 873.

8. Paul, R.; Borah, A.; Sci. Rep. 2017, 7, 17922.

9. Geldmacher, D. S.; Aging Health 2007, 3, 483.

10. Araújo, C. R. M.; Santos, V. L. A.; Arlan, A. G.; Rev. Virtual Quim. 2016, 8, 1818.

11. Handa, S. S.; Khanuja, S. P. S.; Longo, G.; Rakesh, D. D.; Extraction Technologies for Medicinal and Aromatic Plants; ICS Unido: Trieste, IT, 2008. 
12. Ellman, G. L.; Courtney, K. D.; Andres, V.; Featherstone, R. M.; Biochem Pharmacol. 1961, 7, 88.

13. Becker, M. M.; Nunes, G. S.; Ribeiro, D. B.; Silva, F. E. P. S.; Catanante, G.; Marty, J.-L.; J. Braz. Chem. Soc. 2019, 30, 1108.

14. Re, R.; Pellegrini, N.; Proteggente, A.; Pannala, A.; Yang, M.; Rice-Evans, C.; Free Radical Biol. Med. 1999, 26, 1231.

15. Chan-Zuckerberg; UCSF Chimera, version 1.13.1; Biomedicinal Technology Research Resource, University of California, USA, 1970.

16. Apache; Autodocktools, version 1.5.7 rc1; The Scripps Research Institute, La Jolla, USA, 2007.

17. Oleg Trott; AutoDock Vina, version 1.1.2; Molecular Graphics Lab at The Scripps Research Institute, California, USA, 2010.

18. Hanell, M. D.; Curtis, D. E.; Lonie, D. C.; Vandermeersh, T.; Zurek, E.; Hutchison, G. R.; Avogadro, version 1.2.0; University of Pittisburgh, Pittsburgh, USA, 2012.

19. Joshua Gould; Morpheus; Broad Institute, 2015, available at https://software.broadinstitute.org/morpheus/, accessed in November 2021.

20. Dassault Systèms Biovia; Discovery Studio Visualizer, version 20.1.0.19295; California, USA, 2019.

21. Cheung, J.; Rudolph, M.; Burshteyn, F.; Cassidy, M.; Gary, E.; Love, J.; Height, J.; Franklin, M.; Height, J.; J. Med. Chem. 2012, 55, 10282.

22. Lucio, F. N. M.; da Silva, J. E.; Marinho, E. M.; Mendes, F. R. S.; Marinho, M. M.; Marinho, E. S.; Int. J. Res. GRANTHAALAYAH 2020, 8, 221.

23. Guerra, T. M.: Estudos de Docking Molecular de Derivados da Tiazolidina Como Potenciais Inibidores da Enzima Cruzaína de Trypanosoma cruzi; Universidade Federal Rural de Pernambuco, Serra Talhada, Brazil, 2019, available at https://repository.ufrpe.br/bitstream/123456789/1318/1/ tcc_thamilamenezesguerra.pdf, accessed in November 2021.

24. Silva, J.; Marinho, M. M.; da Silva, J. E.; Marinho, E. M.; Marinho, E. S.; Rev. Expr. Catól. Saúde 2018, 3, 35.

25. National Center for Biotechnology Information, PubChem, Bethesda, USA; https://pubchem.ncbi.nlm.nih.gov/, accessed in November 2021.

26. Hanwell, M. D.; Curtis, D. E.; Lonie, D. C.; Vandermeerschd, T.; Zurek, E.; Hutchison, G. R.; J. Cheminf. 2012, 4, 17.

27. Halgren, T. A.; J. Comput. Chem. 1996, 17, 520.

28. Singh, S.; Kumar Gupta, S.; Nischal, A.; Khattri, S.; Nath, R.; Kumar Pant, K.; Kishore Seth, P.; Hepatitis Mon. 2011, 11, 803.

29. Halperin, I.; Ma, B.; Wolfson, H.; Nussinov, R.; Proteins: Struct., Funct., Genet. 2002, 47, 409.

30. Coupez, B.; Lewis, R. A.; Curr. Med. Chem. 2006, 13, 2995.

31. Morgon, N. H.; Coutinho, K. R.; Métodos de Química Teórica e Modelagem Molecular; Livraria da Física: São Paulo, Brazil, 2007.
32. Ma, R.; Xu, X.; Zhao, L.; Cao, R.; Fang, Q.; Int. J. Biomath. 2013, 6, 1350038.

33. Morris, G. M.; Goodsell, D. S.; Halliday, R. S.; Huey, R.; Hart, W. E.; Belew, R. K.; Olson, A. J.; J. Comput. Chem. 1998, 19, 1639.

34. Pettersen, E. F.; Goddard, T. D.; Huang, C. C.; Couch, G. S.; Greenblatt, D. M.; Meng, E. C.; Ferrin, T. E.; J. Comput. Chem. 2004, 25, 1605.

35. Cazarolli, L.; Zanatta, L.; Alberton, E.; Bonorino Figueiredo, M. S.; Folador, P.; Damazio, R.; Pizzolatti, M.; Barreto Silva, F. R.; Mini-Rev. Med. Chem. 2008, 8, 1429.

36. Santangelo, C.; Varì, R.; Scazzocchio, B.; Di Benedetto, R.; Filesi, C.; Masella, R.; Ann. Ist. Super. Sanità 2007, 43, 394.

37. Abdalla, F. H.: Efeito da Quercetina na Atividade de Ectoenzimas e da Acetilcolinesterase em Sinaptossomas do Córtex Cerebral de Ratos Expostos ao Cádmio; MSc Dissertation, Universidade Federal de Santa Maria, Santa Maria, Brazil, 2012, available at https://repositorio.ufsm.br/bitstream/ handle/1/11185/ABDALLA\%2c\%20FATIMA\%20HUSEIN. pdf?sequence=1\&isAllowed=y, accessed in November 2021.

38. Pontual, E. V.: Extrato de Flores de Moringa oleifera: Atividade Larvicida e Efeito sobre Tripsina e Acetilcolinesterase de Larvas de Aedes aegypti; MSc Dissertation, Universidade Federal de Pernambuco, Recife, Brazil, 2010, available at https://repositorio.ufpe.br/bitstream/123456789/1663/1/ arquivo3107_1.pdf, accessed in November 2021.

39. Ngameni, B.; Fotso, G. W.; Kamga, J.; Ambassa, P.; Abdou, T.; Fankam, A. G.; Voukeng, I. K.; Ngadjui, B. T.; Abegaz, B. M.; Kuete, V.; Med. Plant Res. Africa 2013, 301.

40. Heim, K. E.; Tagliaferro, A. R.; Bobilya, D. J.; J. Nutr. Biochem. 2002, 13, 572 .

41. Gibson, G. E.; Huang, H.-M.; Neurobiol. Aging 2005, 26, 575.

42. Santos, T. C.; Gomes, T. M.; Pinto, B. A. S.; Camara, A. L.; Paes, A. M. A.; Front. Pharmacol. 2018, 9, 1192.

43. Balkis, A.; Tran, K.; Lee, Y. Z.; Ng, K.; J. Agric. Sci. 2015, 7, 26.

44. Colovic, M. B.; Krstic, D. Z.; Lazarevic-Pasti, T. D.; Bondzic, A. M.; Vasic, V. M.; Curr. Neuropharmacol. 2013, 11, 315.

45. Cao, J.; Xia, X.; Chen, X.; Xiao, J.; Wang, Q.; Food Chem. Toxicol. 2013, 51, 242.

46. Khan, H.; Marya; Amin, S.; Kamal, M. A.; Patel, S.; Biomed. Pharmacother. 2018, 101, 860.

47. Roca, C.; Requena, C.; Sebastián-Pérez, V.; Malhotra, S.; Radoux, C.; Pérez, C.; Martinez, A.; Antonio Páez, J.; Blundell, T. L.; Campillo, N. E.; J. Enzyme Inhib. Med. Chem. 2018, 33, 1034.

Submitted: March 16, 2021

Published online: November 30, 2021 